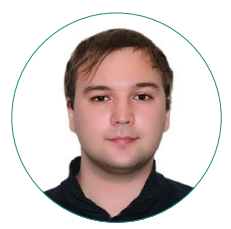

\title{
А. П. Казун \\ ГРОМЧЕ СКАЖЕШЬ - РАНЬШЕ ВЫЙДЕШЬ? ЭТИЧЕСКИЕ И ТАКТИЧЕСКИЕ ОСНОВАНИЯ ИСПОЛЬЗОВАНИЯ ПУБЛИЧНОСТИ КАК ТАКТИКИ СУДЕБНОЙ ЗАЩИТЫ В РОССИИ
}

\section{Правильная ссылка на статью:}

Казун А.П. Громче скажешь - раньше выйдешь? Этические и тактические основания использования публичности как тактики судебной защиты в России // Мониторинг общественного мнения: экономические и социальные перемены. 2021. № 3. С. 450-471. https://doi.org/10.14515/monitoring.2021.3.1892.

\section{For citation:}

Kazun A.P. (2021) If You Make a Noise, Will You Get Freedom Earlier? Ethical and Tactical Factors for Using Publicity as a Tactic of the Defense in the Russian Court. Monitoring of Public Opinion: Economic and Social Changes. No. 3. P. 450-471. https://doi.org/10.14515/ monitoring.2021.3.1892. (In Russ.) 
ГРОМЧЕ СКАЖЕШЬ - РАНЬШЕ ВЫЙДЕШЬ? ЭТИЧЕСКИЕ И ТАКТИЧЕСКИЕ ОСНОВАНИЯ ИСПОЛЬЗОВАНИЯ ПУБЛИЧНОСТИ КАК ТАКТИКИ СУДЕБНОЙ ЗАЩИТЫ В РОССИИ

КАЗУН Антон Павлович - кандидат социологических наук, старший научный сотрудник Международного центра изучения институтов и развития, Национальный исследовательский университет "Высшая школа экономики", Москва, Россия

E-MAIL: kazun.anton@gmail.com https://orcid.org/0000-0002-0091-5388

Аннотация. Российские СМИ нередко освещают судебные дела, те или иные обстоятельства которых могут представлять общественную значимость. В ряде случаев такое внимание возникает неслучайно и является частью тактики одной из сторон процесса. В статье на материалах экспертных интервью с адвокатами и судебными журналистами рассматриваются факторы использования публичности как тактики защиты на судебном процессе. Показано, что мотивы и возможности привлечения внимания публики через СМИ могут существенно различаться в зависимости от обстоятельств дела, а цели подзащитного, адвоката и журналиста не во всех случаях совпадают. В ситуации несовпадения целей наиболее ярко проявляются профессионализм и этические ценности участников процесса. Ввиду высокой гетерогенности как юридического, так и журналистского сообщества на практике встречаются и профессиональные, и эгоистические мотивы повышения уровня публичности судебного процесса. Кроме того, сам статус тактики привлечения внимания СМИ в адво-
IF YOU MAKE A NOISE, WILL YOU GET FREEDOM EARLIER? ETHICAL AND TACTICAL FACTORS FOR USING PUBLICITY AS A TACTIC OF THE DEFENSE IN THE RUSSIAN COURT

Anton P. KAZUN ${ }^{1}$ - Cand. Sci. (Soc.), Senior Research Fellow at the International Center for the Study of Institutions and Development

E-MAIL:kazun.anton@gmail.com https://orcid.org/0000-0002-0091-5388

${ }^{1}$ HSE University, Moscow, Russia

Abstract. Russian mass media often cover court cases, certain circumstances of which may be of public importance. In some cases, such attention arises for a reason as a part of the tactics of one of the litigants. In this article, based on the materials of expert interviews with criminal defense lawyers and court journalists, the author considers publicity as a tactic of defense in the trial. It is shown that the motives and possibilities of attracting the attention of the public through the media can differ significantly depending on the circumstances of the case, and the goals of the client, the lawyer, and the journalist do not coincide in all cases. The professionalism and ethical values of the participants are most clearly manifested in situations of mismatching goals. Due to the high heterogeneity of legal and journalistic communities, we can observe both professional and selfish motives for increasing the level of publicity of the trial. Besides, the status of tactics to attract media attention in the legal community remains controversial due to the uncertain level of its effectiveness and unpredictable consequences. Nevertheless, the analysis shows that 
катском сообществе остается противоречивым ввиду неопределенного уровня ее эффективности и непредсказуемости последствий. Тем не менее анализ показывает, что все участники судебного процесса по меньшей мере принимают во внимание наличие общественного резонанса, а также используют конкретные тактики и стратегии для управления этим фактором.

Ключевые слова: адвокаты, журналисты, профессионализм, СМИ, судебные дела, тактики защиты, этика

Благодарность. Автор выражает признательность за ценные комментарии о проекте исследования Элле Панеях, Алексею Титкову, Ольге Зевелёвой и Виктору Вахштайну. Исследование было бы невозможно без журналистов и адвокатов, любезно согласившихся дать интервью для данного проекта. all participants in the trial at least consider the possibility of public resonance, and use certain tactics and strategies to manage this factor.

Keywords: attorneys, journalists, professionalism, mass media, court cases, defense tactics, ethics

Acknowledgments. The author is grateful for the valuable comments on the project to Ella Paneah, Alexei Titkov, Olga Zeveleva, and Viktor Vakhstein. The study would have been impossible without journalists and lawyers who kindly agreed to be interviewed for the project.

\section{Введение}

Вопросы правоприменения все чаще привлекают внимание ведущих информационных изданий России. В публичном поле оказываются как истории, имеющие яркую политическую окраску, так и сюжеты, не связанные с политикой. В качестве примеров последних можно назвать драку с известными футболистами в 2018 г. $^{1}$ и ДТП с участием актера Михаила Ефремова в 2020 г. Не меньшее внимание порой привлекают и громкие дела по экономическим преступлениям, как связанные с обвинениями в коррупции крупных чиновников, так и те, что могут рассматриваться как проявление силового давления на бизнес [Rochlitz, 2014]. Пример одного из наиболее громких недавних дел о мошенничестве - уголовное преследование американского предпринимателя Майкла Калви, вызвавшее широкий общественный резонанс как в России, так и за рубежом².

Количество уголовных дел по любой из вышеперечисленных категорий (пьяные драки, ДТП, дача взятки, мошенничество и пр.) ежегодно исчисляется тысячами, но лишь единицы попадают в публичное поле. Иногда это происходит помимо воли самих участников ввиду высокой общественной значимости, но в других ситуа-

1 См., например: Кассационный суд постановил пересмотреть дело Кокорина и Мамаева // Коммерсантъ. 2020. 13 мая. URL: https://www.kommersant.ru/doc/4343138 (accessed 17.05.2021).

2 См., например, подборку материалов по данному кейсу: https://www.kommersant.ru/theme/3156 (accessed 17.05.2021). 
циях обращение к СМИ становится частью тактических действий одной из сторон процесса. Результаты использования тактики публичной защиты также сильно различаются: от историй, когда общественная огласка способствовала оправданию (см., например, "дело химиков" [Yakovlev, Sobolev, Kazun, 2014] и дело Ивана Голунова ${ }^{3}$ ), до крайне негативных результатов общественного внимания (примером может быть дело Михаила Ефремова).

В настоящем исследовании мы ставим вопрос о том, как принимаются решения об использовании публичной тактики защиты на суде, а также каковы цели и ожидания сторон, которые ее используют. Ключевые акторы, реализующие данную тактику защиты,- -адвокаты и журналисты. Деятельность этих двух профессиональных групп регулируется этическими нормами, а также ограничивается особенностями институциональной среды. Мы предполагаем, что анализ процесса принятия решения об использовании публичности как тактики защиты может рассказать многое не только о статусе этой практики в современной России, но и о профессиональных сообществах адвокатов и журналистов, обращающихся к ней.

Для ответа на поставленный вопрос нам необходимо понять, какие цели преследуют адвокат, выбирая или не выбирая тактику публичной защиты, и журналист, принимающий решение об освещении того или иного вопроса, а также сопоставить эти цели между собой, найдя возможные несоответствия. Нам также необходимо поместить этот вопрос в контекст российских правовых институтов, очерчивающих границы возможностей участников судебного процесса, и в контекст институциональных условий работы журналистов, являющихся важным фактором донесения информации до общества.

\section{Теоретическая рамка исследования}

До формирования методологической и эмпирической стратегии настоящего исследования нам необходимо с опорой на российские и зарубежные эмпирические исследования ответить на три базовых вопроса:

1) Каково положение адвокатов и журналистов как профессионалов в современной России, а следовательно, каково их влияние на судебный процесс?

2) Какой эффект может иметь освещение дела в СМИ на результаты судебного процесса?

3) Как особенности правовых институтов России влияют на эффекты, которые может иметь публичное освещение судебного процесса?

\section{Российские адвокаты как профессиональная группа}

Адвокатская деятельность - одна из немногих сфер занятости в России, которую почти безоговорочно можно отнести к категории "профессия" (в терминах, предложенных [Abbott, 1988; Brante, 1988; Parsons, 1939]). Во-первых, адвокаты однозначно обладают определенной профессиональной юрисдикцией: только юрист, имеющий статус адвоката, может представлять интересы клиента в российском суде по уголовному делу. Во-вторых, существуют серьезные требования к профессиональной квалификации адвоката: наличие юридического образования,

\footnotetext{
3 Дело Ивана Голунова, см. подборку материалов в газете «Коммерсант»: https://www.kommersant.ru/theme/3212 (accessed 17.05.2021).
} 
опыта работы, необходимость сдачи специального экзамена. В-третьих, есть достаточно развитая профессиональная корпорация, представленная Федеральной палатой адвокатов - крупнейшим в России НКО, действующим на основании собственного закона, а также региональными палатами адвокатов и профессиональными ассоциациям. В-четвертых, адвокаты обязаны следовать нормам профессиональной этики (Кодексу профессиональной этики адвоката от 31 января 2003 г.), за нарушение которых может следовать исключение из профессии.

Вместе с тем нельзя сказать, что «профессиональный проект» российской адвокатуры завершен и достиг успеха [Kazun, Yakovlev, 2017]. Среди ключевых причин незавершенности можно отметить следующие:

- высокий уровень зависимости рядовых адвокатов от вознаграждения за работу «по назначению", то есть от защиты граждан, за которых платит государство [Казун, 2015];

- высокий уровень гетерогенности профессионального сообщества (в части дохода, квалификации, профессиональных ценностей (см. подробнее [Казун, Ходжаев, Яковлев, 2015]);

- регулярное давление на адвокатов и адвокатуру со стороны государства, а также недостаточность инструментов для "очистки" собственных рядов от недобросовестных представителей профессии.

Яркий пример последней слабости профессии адвоката в России - развитие уже упомянутого ранее "дела Ефремова". Как действия адвоката обвиняемого, так и действия адвоката семьи погибшего профессиональное сообщество оценило негативно из-за чрезмерно активной публичной активности и "театрализации" судебного процесса. Эльман Пашаев, представлявший интересы Михаила Ефремова, даже был лишен адвокатского статуса ${ }^{4}$. Нюанс состоит в том, что ранее Эльман Пашаев уже лишался статуса адвоката, а затем получал его вновь в адвокатской палате другого региона, поскольку формальные правила не запрещают этого. Более того, в России лишение статуса адвоката не означает запрет на профессию: юрист все еще может работать в судах по любым типам дел, кроме уголовных. В том числе по этим причинам адвокатская профессия в России остается крайне гетерогенной, а значит, смыслы и цели использования той или иной тактики защиты могут сильно различаться, равно как и отношение к их целесообразности и эффективности.

\section{Российские журналисты как профессиональная группа}

Отнесение российских журналистов к категории классической «профессии" - вопрос существенно более спорный, поскольку в их случае соблюдается еще меньшее количество условий успешного "профессионального проекта". Профессиональная и независимая журналистика в современной России за исключением небольшого числа изданий остается на периферии (в краудфандинговых проектах, YouTube-каналах), в то время как основная часть СМИ находится под прямым контролем государства или связанных с ним групп интересов [Ledeneva, 2013; Lowrey, Erzikova, 2010], что стало следствием политических процессов, про-

\footnotetext{
${ }^{4}$ См., например: Эльмана Пашаева лишили статуса адвоката // РБК. 2020. 18 сентября. URL: https://www.rbc.ru/ society/18/09/2020/5f64b86d9a7947071c8d23e8 (accessed 17.05.2021).
} 
исходивших в России в последние 20 лет. Поскольку требование о независимости не выполняется, то профессию нельзя назвать "свободной", скорее речь идет о журналисте как о наемном работнике, деятельность которого контролируется не профессией, а организацией. По этой же причине нередко на второй план отходят и требования к профессиональной квалификации и образованию, а на первом оказывается вопрос лояльности [Roudakova, 2009]. Свойственны журналистике как проблема прямой цензуры, так и проблема самоцензуры [Zeveleva, 2019].

Вместе с этим нельзя сказать, что в России нет профессиональных журналистов. Наряду с журналистами, выполняющими скорее технические задачи, остается небольшой сегмент профессионалов, для которых значима профессиональная этика [Байтимерова и др., 2018]. Если же говорить о сегменте судебной журналистики, то именно в нем работает немало профессиональных журналистов.

Ввиду вышеназванных особенностей вопрос об этике решается скорее внутри отдельных изданий, чем внутри корпорации в целом. Таким образом, как и в случае с адвокатами, мы можем говорить о высоком уровне гетерогенности сообщества журналистов. По этой причине стоит ожидать, что смыслы и цели подготовки публикаций о тех или иных судебных процессах могут серьезно различаться между собой.

\section{Публичная тактика защиты}

Рассмотрим, что представляет собой тактика привлечения внимания публики к тому или иному судебному делу (в ряде случаев - к делу на этапе ведения следствия). Ответ на данный вопрос могут дать исследования по тематике "медиа и право", большая часть которых посвящена анализу ситуации в США и Европе.

Согласно теории публичных арен С. Хилгартнера и Ч. Боска [Hilgartner, Bosk, 1988], социальные проблемы конкурируют между собой за внимание СМИ, поскольку место в последних естественным образом ограничено. Телеэфир имеет стандартную продолжительность, газеты ограничены числом печатных знаков; у интернет-издания, казалось бы, нет таких естественных лимитов, но их имеет внимание аудитории: публика не сможет одновременно реагировать на большее число тем. Более того, в целом для публики характерно концентрировать внимание всего на нескольких или даже на одной проблеме или событии [Kazun, 2020], которые будут вытеснять собой все прочие.

В этом контексте важный для нас блок научной литературы посвящен вопросу о том, как журналисты принимают решение о том, какие сюжеты освещать, а какие нет [Calvin, Collins, Eshbaugh-Soha, 2011; Collins, Cooper 2015; Strother, 2017]. Ключевой категорией выступает "общественная значимость", которая, однако, разбивается на множество дополнительных подкатегорий, включая вопросы о последствиях (того или иного прецедента), эмоциональной окрашенности проблемы, справедливости и т. д. Для нашего исследования важно, что общественная значимость заложена в обстоятельствах конкретного дела, которые накладывают очень важное ограничение на использование тактики публичной защиты.

Второй блок исследований рассматривает влияние освещения дела в СМИ на общественное мнение [Hitt, Searles, 2018; Kramer, Kerr, Carroll, 1990; Liebman, 2005]. Согласно теории установления повестки дня [Wanta, Golan, Lee, 2004], 
увеличение количества информации о той или иной проблеме способно переключить внимание публики на нее, заставить думать о ней. Кроме того, важны и эмоциональная окраска сообщения, и его связи с другими вопросами повестки дня, что в свою очередь может формировать конкретное мнение о проблеме.

Общественное внимание к делу ("общественный резонанс") иногда влияет на решения судов, чему посвящен третий блок литературы [Boyd, Nelson, 2017; Calvin, Collins, Eshbaugh-Soha, 2011; Glick, Pruet, 1985; Haggerty, Haggerty, 2003; Nelson, 2014]. Например, в работе [Bruschke, Loges, 1999] показано, что для публичных дел вероятность оправдательного приговора выше, но в случае вынесения обвинения приговор оказывается строже. Впрочем, данные исследования не дают оснований для того, чтобы переоценить роль СМИ: судьи в США больше реагируют на юридические факты и конкретные обстоятельства дела, чем на общественный резонанс (хоть и, возможно, вынуждены из-за него писать более длинные обоснования своим решениям [Lim, Snyder, Strömberg, 2015]). Вопрос о влиянии освещения в СМИ на решения российских судов остается слабоизученным.

\section{Институциональные условия реализации публичной тактики защиты в России}

Чтобы понять, насколько корпус литературы о роли СМИ в уголовном процессе зарубежных стран применим к ситуации в России, необходимо рассмотреть ключевые институциональные особенности российского правосудия. Данному вопросу посвящено большое количество российских и зарубежных исследований (см., например, [Волков и др. 2015; Титаев, Шклярук, 2016; Моисеева, Бочаров, 2017]). Отметим на их основе лишь некоторые ключевые особенности, важные для предмета настоящей статьи.

Первая особенность российского правосудия связана с так называемым обвинительным уклоном. Если уголовное дело было возбуждено и попало в суд, то оно с большой долей вероятности закончится обвинительным приговором (уже много лет доля оправданий составляет менее 0,5\%). Это означает, что ключевую значимость приобретает этап следствия, а судьи вольны лишь корректировать приговор в заданных рамках: назначать более мягкое наказание или условный срок, но не оправдывать [Paneyakh, 2016]. Вторая особенность связана с «палочной системой отчетности" [Paneyakh, 2014], предполагающей постоянный рост показателей эффективности работы правоохранителей и судей. В рамках данной системы оправдание или даже возвращение дела на доследование воспринимается как негативный сигнал, который может привести сторону обвинения к потере премии или даже увольнению. Таким образом, из-за "палочной системы отчетности" остановить уголовное дело бывает непросто. Адвокат в данной системе может рассматриваться как помеха для достижения оптимальных показателей, и потому нередки ситуации, когда совершаются процессуальные ошибки, нарушаются права подзащитного, а иногда и самого адвоката.

Все вышеперечисленное, безусловно, негативно сказывается на статусе адвоката в обществе и его внутренней готовности продолжать профессиональную деятельность. Зачем нужно платить профессионалу, если он почти ни на что не может повлиять? Ответ на этот вопрос, в частности, дается в работе [Ходжаева, Рабовски, 2015], где рассматриваются тактики адвокатов как “слабой стороны" в судеб- 
ном процессе. Несмотря на слабую институциональную позицию, российские адвокаты способны добиваться определенных результатов. В рамках настоящего исследования обращение в СМИ рассматривается именно как один из вариантов подобных тактик "слабой стороны", в ответ на которые сильная сторона может использовать как стратегии (выходящие за рамки конкретного кейса действия), так и контртактики (действия, направленные на конкретный судебный процесс).

\section{Методология}

Настоящее исследование основано на 18 экспертных интервью с юристами и судебными журналистами, представляющими две ключевые стороны, участвующие в реализации публичной тактики защиты на судебном процессе. Всего было собрано 10 интервью с юристами (из них 9 имеют статус адвоката, 1 работает помощником адвоката) и 8 интервью с журналистами, представляющими различные российские издания, регулярно освещающие правовые вопросы и судебные дела.

Важно отметить, что наша выборка смещена в сторону наиболее профессиональной части сообщества, то есть мы не говорили с адвокатами, которые носят деньги в суд, или с журналистами, занимающимися размещением компромата за деньги, но, безусловно, спрашивали наших информантов в том числе и о таких практиках, реализуемых другими людьми. Отметим также, что поле судебной журналистики в России достаточно небольшое, профессионалы, работающие в этой сфере, зачастую хорошо знают друг друга. Тем самым даже относительно небольшое количество интервью позволило охватить ключевых участников этого поля, работающих в наиболее авторитетных российских изданиях. Мы не приводим список изданий, поскольку само упоминание издания может позволить почти однозначно идентифицировать судебного журналиста, но будем указывать целевую аудиторию как ключевую характеристику издания: деловое, профессиональное (юридическое) или массовое.

Общение с экспертами проводилось по полуструктурированным гайдам, включающим как общие вопросы о роли публичности в уголовном процессе в России, институциональных и профессиональных аспектах реализации этой тактики, так и вопросы о личном опыте и конкретных кейсах, в которых реализовывались публичные тактики защиты. Упоминания конкретных людей, названий организаций или изданий были удалены из цитат для сохранения конфиденциальности.

\section{Результаты исследования}

Рассмотрим реализацию тактики публичной защиты на судебном процессе, двигаясь в хронологической последовательности. Сначала ответим на вопрос, как принимается решение в пользу реализации публичной тактики судебной защиты, в каких случаях это решение принимается, а в каких отдается предпочтение другим способам защиты. Ответ на этот вопрос неразрывно связан с анализом целей, которые могут преследовать участники процесса, пытаясь придать огласке судебный кейс. Далее проанализируем факторы, способствующие или препятствующие увеличению уровня публичности той или иной истории (в логике теории [Hilgartner, Bosk, 1988]). После этого обсудим последствия, которые данные тактики могут иметь (в зависимости от тех или иных целей их реализации). Наконец, 
в завершение опишем, какие контртактики и контрстратегии может использовать противоположная сторона.

Цели реализации публичной тактики защиты

Для чего может понадобиться привлечь внимание общества к судебному делу? Адвокаты в целом сходятся в том, что эта тактика оправдана, если обоснованные и профессионально сформулированные юридические аргументы по каким-то причинам оказались не услышаны судьей или же если было допущено большое количество процессуальных нарушений.

В то же время адвокату очень важно быть в каком-то плане медийной личностью. В первую очередь - когда мы сталкиваемся с такими вещами, которые можно охарактеризовать как беспредел. Медийность тут может помочь сдвинуть все с мертвой точки. (Адвокат, Москва, интервью № A7)

Если говорить о проблеме шире, то адвокаты на судебном процессе всегда имеют дело с минимальными шансами на позитивный исход (с учетом описанных выше институциональных условий). Привлечение внимания публики через СМИ может повысить шансы на позитивный результат. Важно понимать и то, как ситуация выглядит с обратной стороны. Как показывают исследования [Волков и др., 2015], судья в России имеет дело с большим потоком однотипных дел. Если разделить рабочее время судьи на число дел, которые необходимо рассмотреть, то окажется, что на внимательное ознакомление с материалами дела у него нет времени. В этом контексте публичное внимание к делу выделяет его из числа остальных, делает более заметным для судьи и может побудить внимательнее посмотреть его. Одновременно с этим придание огласке тех или иных процессуальных нарушений, безусловно, не понравится стороне обвинения, что может ограничить возможности для переговоров.

Если юрист <...> проанализировал [предыдущий опыт ${ }^{5}$ вот этого судьи, у которого будет рассматриваться дело, видит, что у него достаточно адекватный послужной список, нормальный бэкграунд, он сходил на первые два заседания, процесс вроде как тоже идет ровно, уважительно, судья выслушивает все аргументы, позиция у тебя достаточно сильная и все нормально - тогда обращаться [в СМИ] не стоит. (Журналист, профессиональное издание, интервью № J5)

Мы привели лишь описание общей логики, стоящей за тактиками публичной защиты, поскольку существенное влияние на ее осуществление оказывают конкретные обстоятельства дела, позиция клиента и позиция адвоката. Проведенные интервью с адвокатами позволяют выделить несколько типичных целей реализации публичной тактики защиты, которые могут быть как ориентированы на сам процесс, так и выходить за его пределы.

\footnotetext{
5 Здесь и далее в квадратных скобках приводятся уточнения от автора относительно контекста, в котором сделано то или иное высказывание.
} 
Цели, ориентированные на процесс, связаны с попыткой прямо или косвенно повлиять на исход дела. Помимо упомянутой попытки привлечь внимание судьи, это может быть стремление надавить на следователей (реже судей) через привлечение внимания профессионального юридического сообщества или даже начальников к судебному процессу.

Наконец, адресатом иногда выступает "противоположная сторона", инициировавшая дело. В отдельных случаях обращение в СМИ может стать сигналом для противоположной стороны (например, компании-конкурента, осуществляющей рейдерскую атаку), что подзащитный готов идти до конца, инвестировать ресурсы в свою защиту, а значит, издержки продолжения атаки на него могут оказаться высокими. В качестве примера приведем следующий случай:

Мы обозначаем [через СМИ], что заявление было изначально подано незаконно. Условно, чтобы человек [противоположная сторона] понимал, что никакого преступления нет, что за человеком за самим есть несколько грехов, о которых мы знаем и которые мы тоже в свою очередь можем использовать как контраргументы... Потому что мы понимали, с какой целью было возбуждено уголовное дело, что вообще не цель привлечения виновного лица к ответственности, а там было именно - ну, такая прямая попытка рейдерства с помощью возбуждения уголовного дела на нынешнего владельца компании. Ну, и с целью обозначить, что мы все это понимаем и мы можем этому противодействовать, вот мы дали такое интервью. (Помощник адвоката, Москва, интервью № A4)

Цели публичной тактики защиты могут находиться и вне процесса. Например, важным мотивом использования тактики защиты через СМИ (а также, что немаловажно, отказа от ее использования) является вопрос профессиональной репутации.

Люди бизнеса, вы понимаете, это такие огромные репутационные потери для людей. <...> Я их спрашиваю - кто вас поддерживает, что у вас в жизни происходит? И вот они говорят, что кто-то, когда это слышит [про уголовное дело], сразу отворачивается, как будто черная чума наступила, то есть перестают общаться. Поэтому описывать какие-то свои уголовные дела? - Нет, я о них нигде не говорю, не пишу. (Адвокат, Москва, интервью № А6)

Даже если предприниматель не рассчитывает на победу в суде, ему может быть важно показать своим деловым партнерам или просто близким людям, что он не мошенник и дело против него возбуждено несправедливо. Или же, напротив, он постарается избежать лишнего шума, чтобы в процессе не всплыли дополнительные неблагоприятные для деловой репутации обстоятельства, которые, например, обнародует сторона обвинения при реализации своей контртактики.

В ряде случаев по инициативе клиента или адвоката дело может подаваться в СМИ как часть более масштабного и серьезного процесса (например, опасный для отрасли прецедент). Такие действия выходят далеко за рамки конкретного судебного дела и имеют целью поменять общественное мнение, пролоббировать 
законодательные изменения, привлечь к ответственности недобросовестных правоохранителей (что, впрочем, происходит редко).

Наконец, в ряде интервью звучали и другие возможные мотивы привлечения внимания СМИ, в том числе идущие вразрез с профессиональной этикой. Например, адвокат через громкий публичный процесс может стремиться увеличить свою известность ("попиариться") и привлечь новых состоятельный клиентов.

Многие молодые адвокаты, причем не только молодые, им кажется, что попасть в газету или дать интервью телеканалу - это большой успех, а кто-то считает, что это определенный канал продаж, как они говорят. Я долгое время комментировал различные ситуации для наших федеральных каналов, и на радио принимал участие. Так вот, я всем своим коллегам хочу передать, что это не дает каких-то больших продаж, это не приведет вам звездных клиентов. (Адвокат, Москва, интервью № A7)

По мнению профессиональных адвокатов, эта тактика, вероятнее всего, навредит клиенту, но совершенно не обязательно будет иметь позитивные последствия для самого адвоката.

Причина первая в том, что адвокату нужно выслуживаться перед клиентом. То есть сказать: клиент, смотри, если мы с тобой пойдем в суд, я тут же прессу привлеку, подниму хайп, все об этом будут писать и все будут за тебя! При этом клиенту не говорят, что это [привлечение внимания СМИ] абсолютно бесполезная вещь. (Адвокат, Краснодар, интервью № АЗ)

Важно указать, что для профессионального адвоката именно определяющей выступает позиция клиента. Если клиент против того, чтобы адвокат давал комментарии в СМИ или, например, шел на телепередачу "Пусть говорят" (иногда в передаче участвуют юристы, работающие в громких процессах), то он не имеет права это делать: обратное будет означать нарушение норм профессиональной этики.

Из перечисленных целей можно сделать вывод о наличии нескольких возможных ситуаций несовпадения позиций адвоката и клиента. Выделяется как минимум три мотива для использования публичной тактики защиты, которые есть у сторон процесса: личная выгода, профессиональный/практический результат и общественные изменения. Если мотивы клиента и адвоката не совпадают между собой, то может возникнуть конфликт. Так, адвокат, реализующий публичную тактику защиты ради личной выгоды, может навредить клиенту. Адвокат, который видит в конкретном деле опасный прецедент и использует его для осуществления тех или иных общественных изменений (например, изменения общественного мнения), также может навредить клиенту (а более суровый приговор способен даже усилить эффект от такой активистской тактики). Разумеется, обе ситуации неприемлемы для профессионального адвоката, но, как было отмечено, адвокатская профессия гетерогенна и в ней в том числе находятся люди, использующие такие непрофессиональные тактики.

Возможна и обратная ситуация, когда доверитель сам решает сделать из своего дела громкое событие, даже если приговор в итоге будет строже. В этом случае 
адвокат оказывается в непростом положении, если он сомневается в эффективности такой тактики. Универсальных ответов о действиях в данной ситуации не существует, и итоговое решение должно приниматься в диалоге с клиентом. Как показывают зарубежные исследования [Johnson 1980; Kritzer 1998], от адвоката зависит очень многое, поскольку именно он является носителем профессиональных знаний о процессе, которых у большинства клиентов нет.

\section{Общественная значимость как ключевой фактор внимания СМИ}

Выше мы рассмотрели только первый этап принятия решения об использовании публичной тактики защиты. Но даже если адвокат и его доверитель единодушно считают, что публичность делу не повредит, это не означает, что она может быть реализована. Здесь в игру вступают журналисты и редакторы изданий, освещающие судебные процессы: именно они решают, является ли дело общественно значимым.

Категория "общественная значимость" для многих информантов-журналистов представляется интуитивно понятной. В большинстве ситуаций не возникает вопроса о том, достойно ли дело общественного внимания, так как все видят, что "дело громкое». Парадокс в том, что именно внимание СМИ делает дело громким. По этой причине нам было важно в разговоре "проблематизировать" для информантов категорию общественной значимости. Отдельный блок вопросов в гайде был посвящен проблеме выбора дел для освещения. В процессе проведения интервью оказалось, что "общественная значимость" не так однозначна, как кажется на первый взгляд.

Перечислим ключевые параметры, которые, по мнению журналистов, предопределяют большое внимание к делу. Самый очевидный параметр для внимания СМИ - статус человека: уголовное дело против известного политика, крупного чиновника или же селебрити, безусловно, привлечет внимание. Однако это не означает, что дело "общественно значимо". В сущности ДТП, в которое попал Михаил Ефремов, одно из многих. Оно вполне типично для России, повышенное внимание к нему вызвано именно статусом обвиняемого и действиями адвокатов. Однако арест губернатора или министра может свидетельствовать о серьезных политических изменениях в стране, которые являются общественно значимыми.

Тем не менее абсолютное большинство уголовных дел в России никак не затрагивают известных людей. Если журналист трактует историю как "рядовую" и не представляющую общественного интереса, то и взять ее в работу он не сможет:

Пишут в редакцию о том, что уголовное дело против них или кого-то из их родственников: "Пожалуйста, помогите». Ты разбираешься и понимаешь, что это рядовая ситуация. То есть ничего из ряда вон выходящего здесь нет. И если ты про это будешь писать, как бы цинично это ни звучало, это мало заинтересует читателей. (Журналист, деловое издание, интервью № Ј6)

В таком случае важными параметрами оказываются "несправедливость" и "сенситивность". Явные нарушения прав человека или, напротив, явные попытки выгородить нарушителя закона, скорее всего, будут восприниматься обществом 
как несправедливые, а значит, привлекут всеобщее внимание. Ту же функцию может выполнять абсурдность или нелогичность обвинения. Преступления против детей или необоснованное помещение под арест многодетной матери - более чувствительные для общества сюжеты, чем нарушения прав мужчины средних лет. Информанты отмечали, что глава СК РФ после нескольких громких дел теперь часто берет под личный контроль случаи ДТП, в которых пострадали дети.

Экономическим делам оказаться сенситивными или несправедливыми в глазах общества сложнее, поскольку сам тип преступления (мошенничество, растрата, превышение должностных полномочий и т. п.) менее понятен широкой публике и при этом традиционно вызывает недоверие у общества, имеющего относительно невысокий уровень доверия к предпринимателям и особенно крупному бизнесу ${ }^{6}$.

Банкротство абсолютно не из этой серии. Я не смогу написать знакомым в [Название издания] или куда-нибудь еще, на телеканал какой-нибудь и сказать: “Вот, есть банкротство, и там кредитор <...> или отдельный должник не хочет возвращать денежные средства". Это никому не интересно, это слишком сложно для понимания. (Адвокат, Москва, интервью № А8)

Чтобы иметь резонанс, по мнению журналистов, в экономических делах должны фигурировать крупные суммы ("от 100 млн рублей») или же на кону должна стоять судьба предприятия с большим числом работников.

Помимо однозначных громких историй есть тип дел, попадающих в «пограничную категорию", для которой требуется принимать решение. Причем решение не сводится к бинарному выбору освещать / не освещать, необходимо также выбрать интенсивность внимания к кейсу. Журналисты могут написать короткий репортаж с первого и последнего заседания, а могут делать онлайн-репортаж с каждого заседания, приезжая для этого в другой регион. Существует также жанр "расследование", который предполагает серьезную аналитическую работу с материалами дела и фактическое воспроизводство той работы, которую в идеальной ситуации должны делать следователи и судьи. Иными словами, выбор журналиста (или редакции издания) не так прост, поскольку связан в том числе и с ресурсами, доступными для освещения проблемы.

Если говорить о "спросе на внимание СМИ" со стороны клиентов и их адвокатов, то он заведомо превышает предложение. Российские журналисты, пишущие о правовых вопросах, сталкиваются с постоянным потоком просьб обратить внимание на то или иное дело. Эти обращения далеко не всегда преследуют благие цели, равно как не все обращения с благими целями оказываются "общественно значимыми".

При мне было несколько ситуаций, когда к нам приходит или юрист, или представитель бизнеса и говорит: “Я хочу, чтобы вы осветили мой спор таким-то образом». Мы обра-

\footnotetext{
6 По данным опроса "Левада-центра", в августе 2020 г. около четверти населения (23\%) считало, что крупный бизнес вполне заслуживает доверия. Малому и среднему бизнесу доверяют чуть более трети граждан (38\%). См.: Доверие институтам // Левада-центр. 2020. 21 сентября. URL: https://www.levada.ru/2020/09/21/doverie-institutam/ (дата обращения: 17.06.2021).
} 
щаем внимание: “Документы, которые Вы нам демонстрируете, свидетельствуют об обратной позиции. Ваш рассказ абсолютно противоречит фактам, поэтому мы описывать эту историю так, как Вы хотите, не будем". Такие истории бывают, да. Естественно, мы отказываем. (Журналист, профессиональное издание, интервью № J5)

Если дело соответствует критериям общественной значимости, то профессиональный журналист будет освещать его вне зависимости от других факторов. Однако можно ли как-то повлиять на решение об освещении того или иного дела, если оно находится в пограничной категории? В этой ситуации возможны два набора действий, имеющих разную степень легитимности для профессионалов, дорожащих своей репутацией: через дополнительное обоснование значимости или через финансовые ресурсы.

Дополнительное обоснование значимости предполагает поиск адвокатом аргументов, почему данное дело может иметь общественное значение. Одним из стандартных путей является составление подборки других дел с аналогичными обстоятельствами. В таком случае журналист сможет написать уже не об одном кейсе, но о целой серии дел, имеющих потенциал стать массовыми (таким примером может выступить серия арестов российских ученых ${ }^{7}$ ).

Вовлечение в дело журналистов через финансовые ресурсы получило двойственные оценки в профессиональной среде журналистов: от полного отрицания приемлемости данной практики до ее принятия с определенными оговорками. Однозначно негативно оцениваются заказные публикации, которые время от времени появляются даже во вполне уважаемых изданиях. Другой пример негативных практик - "сливы" (термин, используемый информантами) конфиденциальной информации через анонимные телеграм-каналы.

Однако есть и другие истории, в частности "спецпроекты»: профессиональные расследования, выполненные по заказу той или иной фирмы и оплаченные из PR-бюджета. Их отличает прозрачный и профессиональный подход к работе с данными и стремление представить позицию противоположной стороны. Правда, эти истории больше относятся к громким арбитражным делам, чем к уголовным кейсам. Кроме того, их могут позволить себе только состоятельные клиенты.

Критерии [отбора для спецпроектов] чуть ослабевают. Мы можем взять спор и на какиенибудь семьдесят миллионов [вместо 100 или более] и осветить. Но опять же, если к нам придут... ну, маловероятно, что к нам придут из-за спора на один или два миллиона рублей и будут тратить свои деньги еще на медийный ресурс. (Журналист, профессиональное издание, интервью № J5)

В целом из проведенного анализа экспертных интервью с журналистами можно сделать вывод, что мотивы участия журналистов в освещении судебных дел сильно различаются. Они могут быть эгоистичными (получить деньги за публикации, создать "хайп" для повышения числа просмотров) или же, например, активистскими (рассказать о несправедливости). Более того, даже действия журналистов, выпол-

\footnotetext{
7 См.: Челищева В. ФСБ ведет охоту на ученых // Новая газета. 2020. 30 ноября. № 132. URL: https://novayagazeta.ru/ articles/2020/11/27/88134-berut-lyudey-s-opytom-lomayut-zhizni-otnimayut-rabotu-i-zdorovie (accessed 17.05.2021).
} 
няющих свою работу профессионально, могут вступать в конфликт с интересами адвоката и его подзащитного. Профессиональный журналист работает на свою аудиторию, поэтому должен рассказывать об общественно значимых делах даже в том случае, если этого не хотят участники дела и их родственники:

Если наоборот [обвиняемый] не хочет [публичной огласки], ты постоянно под давлением. Постоянно родственники [говорят]: “Ну что вы ездите, что вы пишете?» Это капает на мозги. Если дело серьезное, то у тебя своя работа, у них своя работа. Приезжаешь, рассказываешь. Важно здесь следующий момент понимать: журналист работает для читателя. (Журналист, деловое издание, интервью № J6)

В качестве яркого примера столкновения различных логик освещения судебного процесса можно привести публикацию “Медузы" о возможной причастности фигурантов "дела Сети" к убийству ${ }^{8}$. Журналисты издания "Медуза" обозначили причину публикации как следование профессиональному долгу по раскрытию для читателей общественно значимой информации, но эта публикация резко отличалась от шедшей в этот момент широкой медиадискуссии в поддержку обвиняемых.

Таким образом, журналистам порой приходится принимать непростые решения, которые один из информантов даже описал в терминах врачебной этики:

Потому что первое правило, мне кажется, судебного журналиста - это не навреди. Как ты ни гнался бы за хайпом, нужно включать голову и стараться фильтровать информацию, которую ты выпускаешь. (Журналист, массовое издание, № J2)

\section{Роль профессионализма}

Профессионализм участников, реализующих публичную тактику защиты, играет не меньшую роль, чем общественная значимость или обстоятельства дела. Так, важной составляющей работы судебного журналиста является “перевод" материалов дела с бюрократического или юридического языка на язык, понятный широкой аудитории. Важность этого перевода отмечали как журналисты, так и адвокаты. Непросто рассказать о сложном уголовном процессе, материалы по которому составляют десятки томов. Профессиональный журналист должен выбрать самое важное в деле, написать или рассказать об этом доступным языком. В отдельных случаях необходимо подготовить инфографику, иллюстрирующую различные этапы процесса.

Публичное внимание к делу и "общественный резонанс" не освобождают адвоката от необходимости совершать грамотные действия в рамках юридического поля, чтобы конвертировать полученный общественный успех в конкретные результаты по делу. В качестве иллюстрации важности последнего в одном из интервью адвокат привел в пример историю с рейдерским захватом пансионата на юге России. Еще на стадии судебного разбирательства пострадавшей стороне удалось привлечь широкое внимание общественности, в результате чего и общество, и представители региональной власти всецело были на их стороне. В связи

\footnotetext{
8 Речь идет о данной публикации: Пошли четверо в лес, а вышли только двое // Meduza. 2020. 21 февраля. URL: https://meduza.io/feature/2020/02/21/poshli-chetvero-v-les-a-vyshli-tolko-dvoe (accessed 17.05.2021).
} 
с этим адвокат не посчитал нужным предпринимать дополнительных юридических действий (в частности, назначить экспертизу). Суд, не получив необходимых материалов со стороны защиты, встал на сторону рейдера.

Таким образом, оптимальный результат публичной тактики защиты требует профессиональных действий как со стороны адвокатов, так и со стороны журналистов.

\section{Эффективность публичной тактики защиты}

Мы рассмотрели цели, которые могут преследовать участники судебного процесса, а также их действия по реализации публичной тактики защиты. Однако остается важный вопрос о том, к каким результатам эта тактика может привести. Для точного ответа на данный вопрос требуется провести количественный анализ судебных дел, которые освещались или не освещались в СМИ, что не входит в задачу настоящего исследования (подобных исследований в России на данный момент нет). По этой причине в настоящем разделе мы сделаем первый шаг в сторону ответа на данный вопрос и остановимся на ожиданиях и субъективных оценках участников этого процесса.

Если посмотреть на громкие судебные кейсы (см. в том числе подборку резонансных историй с участием различных профессиональных групп [Казун, Яковлев, 2020]), то результативность тактики привлечения общественного внимания окажется как минимум противоречивой: в одних случаях она хорошо работает, в других результат оказывается обратным. В целом и мнения наших информантов в отношении эффективности публичной тактики защиты расходятся. Часть адвокатов и журналистов скептически воспринимают надежду на то, что внимание к делу окажет влияние на судью.

Да, конечно, я допускаю то, что многим судьям обидно, когда про них гадости пишут, поэтому они, возможно, на почве таких эмоциональных обид пишут в Верховный суд, мол, давайте все это пресечем. Вы знаете, насколько я за последние 20 лет знаю судей, ни один из них никогда не вынесет решение только в силу того, что его обхаяли в прессе. (Адвокат, Краснодар, интервью № АЗ)

Действительно, ни один судья никогда не признается в том, что общественный резонанс оказал влияние на решение. Более того, судьи неоднократно высказывались негативно о возможности такого давления ${ }^{9}$. Вместе с тем другие информанты отмечали, что публичность все же имеет значение. Сам факт наличия журналистов в зале суда может повлиять на поведение судьи, что хорошо иллюстрирует следующий фрагмент интервью:

Ну вот, кстати, недавно совсем я общалась с адвокатом. Совсем как бы не связано было с его текущим делом, просто вот он говорит: "Я сейчас занимаюсь, например, делами о банкротстве. И некоторые кейсы очень громкие, вопиющие. Могли бы вы, например, приходить на заседания? И, во-первых, суд видит, что сидят журналисты, и..." Ну, короче, пойнт был в том, что “можете ли вы время от времени приходить

\footnotetext{
9 См. например: Судьи предложили наказывать СМИ за давление и необоснованную критику // РБК. 2019.5 декабря.
} URL: https://www.rbc.ru/politics/05/12/2019/5de86f879a7947ce9a8277f0 (accessed 17.05.2021). 
на какие-то заседания, если интересна тема, и все в таком духе, чтобы суд видел, что есть какой-то публичный интерес, и тогда они [судьи] себя совсем иначе ведут на этих заседаниях". (Журналист, профессиональное издание, интервью №J4)

Публичность кейса переводит его в разряд особенных и выделяющихся среди общего потока дел, рассматриваемых судьей. Кроме того, как отмечают информанты, следователи и судьи действительно следят за публичным полем, хотя и не признаются в этом открыто. Так, представители одного из изданий отметили, что от прессслужбы городского суда порой приходят запросы на исправление фактических неточностей в опубликованных материалах. Кроме того, уже после выхода материала отказывавшиеся ранее от комментариев представители стороны обвинения могут изменить мнение и посчитать необходимым представить свою точку зрения.

Есть и другой возможный механизм влияния, который признавали некоторые информанты, но называли маловероятным другие. Пресс-службы судов, СК РФ и прокуратуры регулярно готовят для своих начальников отчеты с результатами мониторинга прессы (куда входят наиболее авторитетные издания), где упоминаются соответствующие ведомства. Если начальник обратит внимание на допущенные процессуальные нарушения или другие обстоятельства, вызывающие негативную общественную реакцию, то может взять дело "на контроль". В этом случае есть вероятность, что сторона обвинения начнет больше прислушиваться к профессиональным аргументам защиты.

Таким образом, публичная тактика защиты потенциально может иметь положительные эффекты, но в целом определенно не является панацеей. Скорее она используется как вспомогательный элемент, сопровождающий профессиональные действия стороны защиты в правовом поле.

\section{Контртактики и стратегии стороны обвинения}

Несмотря на противоречивую эффективность публичной тактики защиты, в целом есть немало свидетельств того, что противоположная сторона воспринимает ее серьезно и предпринимает ответные действия.

Сторона обвинения (в терминах подхода [Ходжаева, Рабовски, 2015]) является "сильной", то есть может использовать не только тактики, но и стратегии. В целом ключевая стратегия противодействия - это различные институциональные ограничения, позволяющие ограничить информацию. Сюда можно отнести как прямой контроль над СМИ (журналисты государственных изданий редко ходят на процессы) и ужесточение требований к НКО, так и практику брать с адвокатов "подписку о неразглашении" ${ }^{10}$ и факты недопуска журналистов в суд, обоснованные эпидемиологической ситуацией ${ }^{11}$. Впрочем, российский судебный процесс публичный, без оснований не пускать на него журналистов для российских судей чревато обратными последствиями: сам недопуск журналиста на заседание суда станет новостью.

\footnotetext{
${ }^{10}$ См. например: Следствие ограничило адвоката Павлова в комментариях по делу Сафронова // Interfax. 2020. 2 сентября. URL: https://www.interfax.ru/moscow/724239 (accessed 17.05.2021).

${ }^{11}$ См. например: Журналистов не пускают в суды Москвы из-за ограничительных мер в связи с коронавирусом // TACC. 2020. 19 марта. URL: https://tass.ru/moskva/8023117 (accessed 17.05.2021).
} 
Если стратегию, связанную с ограничением доступа к информации, реализовать не удается, то возможны тактики, направленные за усложнение или запутывание дела. Это происходит не часто, но в отдельных случаях используется тактика "слива" информации о деле в анонимные телеграм-каналы или издания с низкой профессиональной репутацией. Такие публикации нередко не относятся напрямую к обстоятельствам дела, но могут навредить репутации обвиняемого.

Следствие по большинству дел сливает... По необходимым, неправильно сказатьпо большинству. По необходимым им делам организует сливы в паблик. Мы помним обыски у начальников, руководителей таможенной службы, у министра Улюкаева и у братьев Мамедовых, там все что угодно. Это как бы слив. Слив - некая сжатая, сфокусированная информация, в которую закладывается определенный изначально необходимый политический контекст. (Адвокат, Москва, интервью № А2)

В коммерческих спорах также возможны ситуации, когда обе стороны пытаются через СМИ продвинуть свою точку зрения на события, но это нередко имеет неблагоприятные последствия для всех из-за чрезмерного шума.

\section{Заключение}

В настоящей работе впервые в научной литературе мы описали тактику защиты в российском уголовном процессе, связанную с привлечением внимания к делу через СМИ. Несмотря на то, что данная практика получила смешанные оценки со стороны профессиональных участников процесса, мы увидели, что публичность часто рассматривается и защитой, и обвинением как значимый фактор, способный повлиять на исход дела. Одной из возможных причин роста популярности данного способа защиты, по всей видимости, являются институциональные несовершенства российского правосудия. К публике или к вышестоящим органам власти апеллируют прежде всего в тех ситуациях, когда профессиональные аргументы защиты остаются без внимания. Таким образом, общественное мнение превращается в самостоятельного арбитра, который может вынести свой вердикт вместе с судьей.

Отдельный исследовательский вопрос, требующий дополнительного анализа, состоит в том, почему данная тактика защиты вообще может работать, ведь ее нельзя объяснить, опираясь только на формальные нормы. На основе собранного нами материала можно выдвинуть предположение, что попадание того или иного судебного дела в публичное поле связывает судебное решение по нему с такими ценностями, как справедливость и равенство перед законом. Использование судебной системы против слабых в интересах сильных затруднено в ситуации, когда за этим делом наблюдает публика. Если права подзащитного нарушаются, несмотря на общественное внимание, а суд выносит решение, которое кажется обществу несправедливым, то страдает легитимность правоохранительной системы в целом. В свою очередь, именно риск утраты легитимности может стать одним из важных аргументов для правоохранительных органов и судей, а также их непосредственных начальников в пользу того, чтобы вынести справедливый и обоснованный приговор по делу, которое возникло при сомнительных обстоятельствах. Наиболее 
яркий пример подобной истории - дело журналиста Ивана Голунова ${ }^{12}$, которое было закрыто именно на фоне большого общественного резонанса.

Можно предположить, что в условиях сохранения "обвинительного уклона" и слабости адвокатской профессии тактика публичной защиты на суде будет только набирать популярность в будущем. Способствует этому и развитие новых медиа, поскольку социальные сети позволяют частично преодолеть барьеры, связанные с недостаточностью ресурсов и цензурой, а также привлечь внимание к новым проблемам, которые ранее не попадали в категорию общественно значимых. Однако есть и обратная сторона данного процесса, связанная с адаптацией правоохранительной и судебной систем к публичной тактике защиты. Данная адаптация проявляет себя как в стратегических действиях, связанных с ограничением уровня публичности (давлением на независимых журналистов и адвокатов, включая возбуждение против них уголовных дел, закрытием судебных заседаний под предлогом пандемии или наличия в деле документов, составляющих государственную тайну, и пр.), так и в более тонких тактических действиях, например, по "сливу" неблагоприятной для стороны защиты информации в публичное поле. С учетом существенного перевеса в ресурсах в пользу правоохранительной системы вероятность успешной реализации данных стратегий и тактик можно оценить как очень высокую. Впрочем, полная победа над публичностью может негативно отразиться и на самой системе, ведь она утратит последний механизм "обратной связи" с обществом и, как следствие, серьезную часть собственной легитимности.

\section{Список литературы (References)}

Байтимерова С. И., Богомазова Л. В., Григорьева Е. А., Казун А. Д. Контроль и этика в профессиональной деятельности экономических журналистов // Журнал социологии и социальной антропологии. 2018. Т. 21. № 1. С. 136-160. https:// doi.org/10.31119/jssa.2018.21.1.6.

Baytimerova S., Bogomazova L., Grigoryeva E., Kazun A. (2018) Control and Ethics in Professional Activity of Economic Journalists. Journal of Sociology and Social Anthropology. Vol. 21. No. 1. P. 136-160. https://doi.org/10.31119/jssa.2018. 21.1.6. (In Russ.)

Волков В. В., Дмитриева А. В., Титаев К.Д., Поздняков М. Российские судьи: социологическое исследование профессии. СПб. : Норма. 2015.

Volkov V. V., Dmitrieva A. V., Titaev K. D., Pozdnyakov M. (2015) Russian Judges: A Sociological Study of the Profession. St. Petersburg: Norma. (In Russ.)

Казун А.П. Социальная ответственность российских адвокатов: факторы оказания бесплатной юридической помощи по назначению и pro bono. // Журнал исследований социальной политики. 2015. Т. 13. № 4. С. 563-578. URL: https://jsps.hse. ru/article/view/3300 (дата обращения: 19.05.2021).

Kazun A. P. (2015) Social Responsibility Among Russian Attorneys: Factors Behind the Provision of Free Legal Assistance Both by Court Appointment and pro bono. The

\footnotetext{
12 Дело Ивана Голунова, см. подборку материалов в газете «Коммерсант»: https://www.kommersant.ru/theme/3212 (дата обращения: 17.05.2021).
} 
Journal of Social Policy Studies. Vol. 13. No. 4. P. 563-578. URL: https://jsps.hse.ru/ article/view/3300 (accessed: 19.05.2021). (In Russ.)

Казун А. П., Яковлев, А.А. Как участие врачей, священников и актеров влияет на отношение граждан к акциям в защиту прав человека: результаты эксперимента // Вопросы теоретической экономики. 2020. № 4. С. 29-48. https://doi.org/ 10.24411/2587-7666-2020-10403.

Kazun A. P., Yakovlev A. A. (2020) Influence of Involvement of Physicians, Clergymen and Actors on People's Attitude to Human Rights Campaigns: Results of an Experiment. Questions of Theoretical Economics. No. 4. P. 29-48. https://doi.org/10.24411/25877666-2020-10403. (Russ.)

Казун А. П., Ходжаев Е. А., Яковлев А. А. Адвокатское сообщество России. Доклад ИАПР НИУ ВШЭ и ИПП ЕУ СПб. М., 2015.

Kazun A. P., Khodzhaev E. A., Yakovlev A. A. (2015) Attorneys' Community of Russia. Moscow. (In Russ.)

Моисеева Е. Н., Бочаров Т. Ю. Быть адвокатом в России: социологическое исследование профессии. Издательство Европейского университета в Санкт-Петербурге. 2017.

Moiseeva E. N., Bocharov T. Yu. (2017) Being a Lawyer in Russia: A Case Study of the Profession. EUSP Press. (In Russ.)

Титаев К.Д., Шклярук М.С. Российский следователь. Призвание, профессия, повседневность. М.: Норма. 2016.

Titaev K. D., Shklyaruk M. S. (2016) Russian Investigator. Vocation, Profession, Everyday Life. Moscow: Norma. (In Russ.)

Ходжаева Е.А., Рабовски (Шестернина) Ю. В. Стратегии и тактики адвокатов в условиях обвинительного уклона в России // Социология власти. 2015. № 2. C. $135-167$.

Khodzhaeva E. A., Rabovski (Shesternina) Yu.V. (2015) Strategies and Tactics of Lawyers in the Context of an Accusatory Bias in Russia. Sociology of Power. No. 2. P. 135-167. (In Russ.)

Abbott A. (1988) The System of Professions: An Essay on the Division of Expert Labor. Chicago: University of Chicago Press.

Boyd C. L., Nelson M. J. (2017) The Effects of Trial Judge Gender and Public Opinion on Criminal Sentencing Decisions. Vanderbilt Law Review. Vol. 70. No. 6. P. 1819-1843.

Brante T. (1988) Sociological Approaches to the Professions. Acta Sociologica. Vol. 31. No. 2. P. $119-142$.

Bruschke J., Loges W. (1999) Relationship Between Pretrial Publicity and Trial Outcomes. Journal of Communication. Vol. 49. No. 4. P. 104-120. https://doi.org/10.1111/ j.1460-2466.1999.tb02819.x.

Calvin B., Collins P. M., Eshbaugh-Soha M. (2011) On the Relationship Between Public Opinion and Decision Making in the U.S. Courts of Appeals. Political Research Quarterly. Vol. 64. No. 4. P. 736-748. https://doi.org/10.1177/1065912910376387. 
Collins T. A., Cooper C. A. (2015) Making the Cases "Real": Newspaper Coverage of U.S. Supreme Court Cases 1953-2004. Political Communication. Vol. 32. No. 1. P. 23-42. https://doi.org/10.1080/10584609.2013.879363.

Glick H. R., Pruet G. W. (1985) Crime, Public Opinion and Trial Courts: An Analysis of Sentencing Policy. Justice Quarterly. Vol. 2. No. 3. P. 319-343. https://doi.org/ 10.1080/07418828500088591.

Haggerty J. F., Haggerty J. (2003) In the Court of Public Opinion: Winning Your Case with Public Relations. Hoboken, N.J: Wiley.

Hilgartner S., Bosk C. L. (1988) The Rise and Fall of Social Problems: A Public Arenas Model. American Journal of Sociology. Vol. 94. No. 1. P. 53-78. https://doi.org/ 10.1086/228951.

Hitt M. P., Searles K. (2018) Media Coverage and Public Approval of the U.S. Supreme Court. Political Communication. Vol. 35. No. 4. P. 566-586. https://doi.org/10.108 0/10584609.2018.1467517.

Johnson E. (1980) Lawyers' Choice: A Theoretical Appraisal of Litigation Investment Decisions. Law \& Society Review. Vol. 15. No. 3/4. P. 567-610. https:// doi.org/10.2307/3053503.

Kazun A. (2020) Agenda-Setting in Russian Media. International Journal of Communication. Vol. 14. P. 4739-4759.

Kazun A., Yakovlev A. (2017) Who Demands Collective Action in an Imperfect Institutional Environment? A Case Study of the Profession of Advocates in Russia. Journal of Eurasian Studies. Vol. 8. No. 1. P. 60-71. https://doi.org/10.1016/ j.euras.2016.08.001.

Kramer G., Kerr N., Carroll J. (1990) Pretrial Publicity, Judicial Remedies, and Jury Bias. Law \& Human Behavior. Vol. 14, No. 5. P. 409-438.

Kritzer H. M. (1998) Contingent-Fee Lawyers and Their Clients: Settlement Expectations, Settlement Realities, and Issues of Control in the Lawyer-Client Relationship. Law \& Social Inquiry. Vol. 23. No. 4. P. 795-821.

Ledeneva A.V. (2013) Can Russia Modernise? Sistema, Power Networks and Informal Governance. Cambridge: Cambridge University Press.

Liebman B. L. (2005) Watchdog or Demagogue? The Media in the Chinese Legal System. Columbia Law Review. Vol. 105. No. 1. P. 1-157.

Lim C. S. H., Snyder Jr., J. M., Strömberg D. (2015) The Judge, the Politician, and the Press: Newspaper Coverage and Criminal Sentencing across Electoral Systems. American Economic Journal: Applied Economics. Vol. 7. No. 4. P. 103-35. https:// doi.org/10.1257/app.20140111.

Lowrey W., Erzikova E. (2010) Institutional Legitimacy and Russian News: Case Studies of Four Regional Newspapers. Political Communication. Vol. 27, No. 3. P. 275-288. https://doi.org/10.1080/10584609.2010.494282. 
Nelson M. (2014) Responsive Justice? Retention Elections, Prosecutors, and Public Opinion. Journal of Law and Courts. Vol. 2. No. 1. P. 1-45.

Paneyakh E. (2014) Faking Performance Together: Systems of Performance Evaluation in Russian Enforcement Agencies and Production of Bias and Privilege. PostSoviet Affairs. Vol. 30. No. 2-3. P. 115-136. https://doi.org/10.1080/106058 6X.2013.858525.

Paneyakh E. (2016) The Practical Logic of Judicial Decision Making. Russian Politics \& Law. Vol. 54. No. 2-3. P. 138-163. https://doi.org/10.1080/10611940.2016 .1176843.

Parsons T. (1939) The Professions and Social Structure. Social Forces. Vol. 17. No. 4. P. $457-467$.

Rochlitz M. (2014) Corporate Raiding and the Role of the State in Russia. PostSoviet Affairs. Vol. 30. No. 2-3. P. 89-114. https://doi.org/10.1080/106058 6X.2013.856573.

Roudakova N. (2009) Journalism as “Prostitution”: Understanding Russia's Reactions to Anna Politkovskaya's Murder. Political Communication. Vol. 26. No. 4. P. 412-429. https://doi.org/10.1080/10584600903053890.

Strother L. (2017) How Expected Political and Legal Impact Drive Media Coverage of Supreme Court Cases. Political Communication. Vol. 34. No. 4. P. 571-589. https:// doi.org/10.1080/10584609.2017.1306817.

Wanta W., Golan G., Lee C. (2004) Agenda Setting and International News: Media Influence on Public Perceptions of Foreign Nations. Journalism \& Mass Communication Quarterly. Vol. 81. No. 2. P. 364-377. https://doi.org/10.1177/107769900408100209.

Yakovlev A., Sobolev A., Kazun A. (2014) Means of Production Versus Means of Coercion: Can Russian Business Limit the Violence of a Predatory State? Post-Soviet Affairs. Vol. 30. No. 2-3. P. 171-194. https://doi.org/10.1080/1060586X.2013.859434.

Zeveleva O. (2019) How States Tighten Control: A Field Theory Perspective on Journalism in Contemporary Crimea. The British Journal of Sociology. Vol. 70. No. 4. P. 1225-1244. https://doi.org/10.1111/1468-4446.12615. 